\title{
Эмоционально-волевая готовность к полисубъектному взаимодействию бакалавров физической культуры
}

\author{
Ксения Е. Токарева', Вера С. Макеева ${ }^{1 *}$, Галина А. Ямалетдинова² \\ 1 Московский государственный областной университет, г. Москва, Российская \\ Федерация \\ 2 Гуманитарный университет, г. Екатеринбург, Российская Федерация \\ ${ }^{*}$ E-mail: autonom-l@yandex.ru
}

\begin{abstract}
Аннотация
Ввеление. Формирование эмоционально-волевой готовности бакалавров физической культуры в полисубъектном взаимодействии с участниками озАоровительной тренировки в ффизкультурно-оздоровительном процессе подразумевает многосторонние Аеятельно-ценностные отношения с учетом потребностей, особенностей и возможностей Аруг Аруга. Наличие стихийности процесса на фроне высоких фризических нагрузок и эмоциональная насыщенность взаимодействия требуют решения проблем кажАого клиента, тем самым повышая уровень ответственности за него и проявления эмоционально-волевых усилий. Полагаем, что сознательное управление мышечным тонусом и использование приемов саморегуляции обеспечивают развитие волевых качеств бакалавра. Вместе с тем, решению данной проблемы на этапе вузовской подготовки студентов фракультета фризической культуры не уделяется АОлжного внимания, что не способствует развитию психологически Устойчивой Аичности и повышению качества ее профессиональной готовности. Методы. Использованы методы оценки на основе внешнего проявления эмоций в разработке В.^. Марищука, определения коммуникативной толерантности В.В. Бойко, определения силы воли в разработке Р.С. Немова.
\end{abstract}

Результаты. На исходном уровне сорормированность эмоционально-волевой готовности в обеих группах прояви^ась в основном на среднем и низком уровнях. К концу эксперимента среАний уровень выявлен у $57 \%$, высокий у $43 \%$ респонАентов контрольной группы. В экспериментальной группе это соотношение состави^о $37 \%$ и $63 \%$.

ОбсужАение результатов. Проявление эмоциональной устойчивости опреАеляется возрастными особенностями формирования Я-концепции в послеАовательном формировании самооценки мичности. Эффрективность фрормирования эмоциональной устойчивости опреАеляется реализацией инАивиАуальной и колАективной форм взаимодействия, взаимопомощи и подАержки, свобоАного выбора инАивидуальных залач. Вк^ючение средств йоги, ка^^анетики, пи^атеса, выполняемых 
в статическом режиме и улержании определенных поз, вызывая нервно-психическое напряжение, приводит к активизации эмоционально-волевых усилий.

\section{КАючевые слова}

бакалавр фризической культуры, эмоционально-волевая готовность, эмоциональная устойчивость, толерантность, волевые качества, полисубъектное взаимолействие, субъект озАоровительной тренировки, низкоинтенсивные упражнения, самомотивация, целеполагание

\section{Основные положения}

- эффоективное полисубъектное взаимолействие требует фрормирования эмоционально-волевой готовности бакалавров физической культуры к профрессиональной Аеятельности в связи с ее спецификой: стихийности, эмоциональной насыщенности и значительных фризических нагрузок;

эмоционально-волевая готовность бакалавров ффизической культуры опрелеляется эфффективностью формирования эмоциональной устойчивости, толерантности и волевых качеств Аичности при взаимодействии с незнакомой аудиторией субъектов озАоровительной тренировки;

- приобретение знаний в области полисубъектного взаимодействия с субъектами озАоровительной тренировки, участие в тренингах и психотехнических играх способствуют развитию уверенности, чувства успеха, позитивного мышления и управления негативными психофизиологическими состояниями (инорормационный модуль);

- сознательное управление мышечным тонусом в процессе применения оризических низкоинтенсивных упражнений (йоги, калманетики и Ар.) способствует развитию волевых качеств: терпеливости, спокойствия и вылержки;

- упражнения на развитие целеполагания и самомотивации (развивающий модуль) способствуют фоормированию целеустремленности студентов.

\section{Для цитирования}

Токарева К.Е., Макеева В.С., Ямалетдинова Г. А. Эмоционально-волевая готовность к полисубъектному взаимодействию бакалавров физической культуры // Российский психологический журнал. - 2018. - Т. 15, № 1. - С. 205-227. DOI: 10.21702/rpj.2018.1.10

Материалы статьи получены 10.07.2017 


\title{
Emotional and Volitional Readiness for Polysubject Interaction Among Bachelors in Physical Education
}

\author{
Ksenia E. Tokareva ${ }^{1}$, Vera S. Makeeva ${ }^{1 *}$, Galina A. Yamaletdinova ${ }^{2}$ \\ ${ }^{1}$ Moscow Region State University, Moscow, Russian Federation \\ ${ }^{2}$ The Liberal Arts University, Ekaterinburg, Russian Federation \\ *Correspondence author. E-mail: autonom-I@yandex.ru
}

\begin{abstract}
Introduction. Emotional and volitional readiness for polysubject interaction among the participants of health-improving workouts involves multilateral value relations based on the potential, needs, and characteristics of each other. The spontaneity of the process along with high physical loading and emotional intensity of interaction require solving the problems of each client. The article puts forward the idea that conscious regulation of muscle tone and self-regulation techniques ensure the development of a bachelor's volitional qualities. However, little attention has been devoted to the solution of this problem at the stage of university training of physical education students. This impedes the development of a psychologically stable personality and improvement of professional readiness.
\end{abstract}

Methods. These were the technique for Assessing External Manifestations of Emotions developed by V.L. Marishchuk; General Communicative Tolerance questionnaire developed by V.V. Boiko; Will Power questionnaire developed by R.S. Nemov.

Result. Both groups were characterized by high and low levels of emotional and volitional readiness at the initial stage of the study. At the end of the experiment, $57 \%$ of respondents in the control group had an average level of emotional and volitional readiness; $43 \%$ of respondents had a high level of emotional and volitional readiness. These proportions were $37 \%$ and $63 \%$ for the experimental group.

Discussion. Age-specific characteristics of self-concept determine emotional stability through a sequential formation of self-esteem. Individual and collective forms of interaction, mutual assistance and support, free choice of individual tasks determine the effectiveness of emotional stability. The techniques of yoga, callanetics, and pilates, which are focused on holding certain static poses, lead to mental stress and activate emotional and volitional efforts.

\section{Keywords}

bachelor in physical education, emotional and volitional readiness, emotional stability, tolerance, volitional qualities, polysubject interaction, subject of health-improving workout, low-intensity exercises, self-motivation, goal-setting 


\section{Highlights}

- Effective polysubject interaction requires emotional and volitional readiness for professional activity among bachelors in physical education; this is determined by the specificity of this activity - spontaneity, high physical loading, and emotional intensity of interaction.

- Emotional and volitional readiness among bachelors in physical education is determined by emotional stability, tolerance, and volitional qualities in the process of interaction with the unfamiliar audience of health-improving workouts.

- Knowledge in the field of polysubject interaction with the subjects of healthimproving workouts, participation in trainings and psychotechnical games contribute to the development of confidence, feeling of success, positive thinking, and managing negative psycho-physiological states (the information module).

- When performing low-intensity physical exercises (yoga, callanetics, etc.) conscious regulation of muscle tone helps to develop volitional qualities - patience, calmness, and self-control.

- Goal-setting and self-motivation exercises (the developing module) contribute to students' purposefulness.

\section{For citation}

Tokareva K. E., Makeeva V.S., Yamaletdinova G. A. Emotional and Volitional Readiness for Polysubject Interaction Among Bachelors in Physical Education. Rossiiskii psikhologicheskii zhurnal - Russian Psychological Journal, 2018, V. 15, no. 1, pp. 205-227 (in Russian). DOI: 10.21702/rpj.2018.1.10

Original manuscript received 10.07.2017

\section{Введение}

Современный тренер оздоровительной физической культуры испытывает значительные эмоциональные и физические нагрузки в процессе профессиональной деятельности, специфика которой заключается в необходимости его включения в полисубъектное взаимодействие с различным контингентом занимающихся в физкультурно-оздоровительной деятельности $[1,2,3,4,5$, $6,7,8,9]$. В настоящее время проблема полисубъектности занимает одно из ведущих мест в теоретико-прикладных исследованиях, становится одним из актуальных направлений исследований в развитии и саморазвитии субъектов образовательной среды, в том числе и в физкультурно-спортивной деятельности $[10,11,12,13,14,15,16,17,18]$.

В педагогическом процессе оздоровительной тренировки, когда необходимо со всеми находить общий язык и получать приемлемый результат, вероятность возникновения стресс-факторов прямо пропорциональна 
количеству участвующих субъектов, каждый из которых имеет свои индивидуально-типологические, возрастно-половые и личностные особенности $[7,19$, $20,21,22,23]$. Накопительный характер стресса в тренерской деятельности способствует нарушению адекватности восприятия и оценки угрозы от помехи в учебно-тренировочном процессе, выбора соответствующих тактик реагирования. Кроме того, организация и проведение оздоровительной тренировки в условиях коммерческих физкультурно-спортивных организаций озадачивают тренера не только с позиции моральной ответственности за здоровье и ожидаемый результат «клиентов», но и предъявляют дополнительные требования со стороны руководства к обеспечению им экономической эффективности, которая выражается в выполнении плана продаж собственных услуг [6, 8, 9, 22, 24, 25].

Таким образом, высокая степень непредсказуемости характера взаимоотношений, ситуаций и условий труда, эмоциональная насыщенность взаимодействия, необходимость постоянного проникновения в суть проблемы каждого клиента, высокий уровень ответственности, нередко высокие физические нагрузки - все это требует от любого педагога, и в том числе тренера, проявления значительных эмоционально-волевых усилий. Низкий уровень развития эмоционально-волевой сферы личности тренера, с одной стороны, будет способствовать синдрому «профессионального выгорания», неудовлетворенности профессией, нервным срывам, ухудшению соматического здоровья, и с другой - снижению экономической эффективности, недовольству со стороны руководства и субъектов оздоровительной тренировки. Полагаем, что гармоничному развитию психологически суверенной и здоровой личности профессионала и, как следствие, повышению качества существующей практики оздоровительной тренировки будет способствовать формирование эмоционально-волевой готовности будущих тренеров еще на этапе вузовской подготовки. При этом готовность будет отражать наличие у них определенной совокупности знаний, личностных качеств, способностей и опыта, необходимых для полисубъектного взаимодействия с субъектами оздоровительной тренировки.

Таким образом, целью данного исследования являлась разработка технологии формирования эмоционально-волевой готовности к полисубъектному взаимодействию в процессе профессионального образования бакалавров физической культуры. Для проверки эффективности разработанной технологии были определены показатели, позволяющие осуществлять мониторинг развития эмоционально-волевой готовности: уровень эмоциональной устойчивости в сложных ситуациях взаимодействия, проявляющийся в умении осознанно включать и управлять индивидуальными ресурсами адаптации и защиты, преобразуя стрессовые ситуации из непреодолимых 
в преодолимые; уровень толерантности, определяющий терпимое, бесконфликтное и уважительное поведение, несмотря на неприятные или неприемлемые психические состояния, качества и поступки партнеров по взаимодействию; уровень развития волевых качеств.

\section{Методы}

В эксперименте приняли участие 60 студентов Орловского государственного университета имени И.С. Тургенева, обучающихся по направлению подготовки 49.03.01. «Физическая культура». Контрольную группу составили 30 студентов, поступивших в вуз в 2011 и 2012 гг. В экспериментальную группу вошли 30 студентов 2013 года поступления. Для диагностики уровня развития эмоционально-волевой готовности к полисубъектному взаимодействию был использован следующий оценочный инструментарий: методика оценки проявлений эмоций в мимике, скованности движений, треморе, вазомоторных реакциях в разработке В.Л. Марищука, позволяющая при помощи экспертных оценок количественно оценить качественные проявления эмоционально-волевого состояния студентов в условиях, вызывающих волнение или легкий стресс; методика определения коммуникативной толерантности В.В. Бойко; методика по определению силы воли в разработке Р.С. Немова, основанная на самооценке ситуативных волевых проявлений.

Исследование осуществлялось в начале второго года обучения, до начала реализации технологии формирования готовности к полисубъектному взаимодействию бакалавров физической культуры («исходный срез»), и в конце четвертого курса («конечный срез»). Все количественные характеристики, полученные в процессе исследования, подвергались статистической обработке на основе вычисления U-критерия Манна - Уитни. Посредством метода шкалирования и сопоставительного анализа осуществлялись распределение испытуемых по уровням эмоционально-волевой готовности к полисубъектному взаимодействию и дальнейшая обработка результатов.

Технология формирования эмоционально-волевой готовности бакалавров физической культуры к полисубъектному взаимодействию, которая была реализована в экспериментальной группе, включала внедрение в учебные дисциплины трех взаимосвязанных модулей: информационного, развивающего и квазипрофессионального. Специфика информационного модуля заключалась в трансляции обучающимся инновационных знаний в области полисубъектного взаимодействия в оздоровительной тренировке. Сущность развивающего модуля заключалась в проработке психотехнических игр, ситуационных заданий и упражнений, направленных на развитие толерантности, стрессоустойчивости, эмпатийности, педагогического оптимизма, умения выражать симпатию и т. д. Квазипрофессиональный модуль в рамках 
дисциплин спортивно-педагогического цикла базировался на выработке опыта полисубъектного взаимодействия с субъектами в условиях оздоровительной тренировки посредством реального включения студентов в ситуации, имитирующие профессиональную деятельность тренера. Ведущими методами являлись: проблемные лекции, презентативные лекции, лекциидискуссии, семинары-дискуссии, семинары-конференции однородных групп, кейс-методы, групповой тренинг, микропреподавание, творческая работа, мастер-классы, методы физического воспитания. При этом осуществление процесса подготовки происходило с использованием следующих средств: научных текстов, материалов Учебно-методического центра «Профессионалы фитнеса», видеоматериалов, презентаций PowerPoint, сборника развивающих упражнений, конспектов микротренировок, сценариев физкультурно-оздоровительных и рекреационных мероприятий, опыта тренеров, спортивного ориентирования, спортивных и подвижных игр, эстафет, средств малоинтенсивных фитнес-программ (йоги, калланетики, пилатеса).

\section{Результаты}

Для объективной оценки нами проведено разделение студентов по уровню проявления эмоционально-волевой готовности бакалавров физической культуры к полисубъектному взаимодействию. Студенты, отличающиеся средним уровнем развития эмоциональной устойчивости, характеризуются умеренной регуляцией в стрессовых условиях. Это означает, что обучающийся, попадая в ситуации коллективного взаимодействия и публичного оценивания аудиторией, испытывает легкое волнение, а наличие некоторой психической напряженности вызывает ощущения дискомфорта, однако это не приводит к деструктивным последствиям и большому количеству ошибок. Более того, лица с умеренной эмоциональной устойчивостью способны адаптироваться к стресс-факторам и в целом справляться с волнением посредством волевых усилий.

У респондентов с низким уровнем эмоциональной устойчивости в ситуациях взаимодействия и оценивания группой возникает сильная психическая напряженность, что внешне выражается в нарушении психомоторики, ригидности поведения, двигательной раскоординированности, большом количестве ошибок. Они полностью теряют самоконтроль и не умеют владеть собой. Такое поведение обусловлено специфической реакцией вегетативной нервной системы на стресс-фактор, что приводит к значительным нерациональным тратам физической и нервно-психической энергии. Данные состояния приводят к уязвимости интеллектуальных и вербальных психических функций. При этом длительная психическая напряженность вызывает негативные тенденции в настроении, повышает утомляемость, способствует развитию фрустрации, переориентации мотивов взаимодействия. 
Только к концу эксперимента были зафиксированы респонденты с высокой эмоциональной устойчивостью в ситуациях коллективного взаимодействия и публичного оценивания аудиторией. Это характеризовало наличие у них способности сохранять внутреннее спокойствие, оптимизм, психологическую эмоциональную целостность и высокую эффективность в условиях действия стресс-факторов. Как подчеркивается в исследованиях К.С. Станиславского, высокая эмоциональная устойчивость в совокупности с приобретенными профессиональными знаниями, умениями и опытом открывает возможности к импровизации и творческому самовыражению [26].

Результаты исследования уровня развития эмоционально-волевой готовности бакалавров физической культуры к полисубъектному взаимодействию представлены в таблице 1.

Таблица 1. Аинамика эмоционально-волевой готовности будущих бакалавров фризической культуры к полисубъектному взаимодействию

Table 1. Dynamics of emotional and volitional readiness for polysubject interaction among future bachelors in physical education

\begin{tabular}{|c|c|c|c|c|c|c|c|c|c|}
\hline \multirow{4}{*}{$\begin{array}{c}\text { Показатели } \\
\text { готовности } \\
\text { Charac- } \\
\text { teristics of } \\
\text { readiness }\end{array}$} & \multirow{4}{*}{$\begin{array}{c}\text { Уровни } \\
\text { проявле- } \\
\text { ния } \\
\text { Levels of } \\
\text { manifes- } \\
\text { tation }\end{array}$} & \multicolumn{8}{|c|}{$\begin{array}{c}\text { Этапы эксперимента } \\
\text { Experimental stages }\end{array}$} \\
\hline & & \multicolumn{4}{|c|}{$\begin{array}{c}\text { Экспериментальная } \\
\text { группа } \\
\text { Experimental group }\end{array}$} & \multicolumn{4}{|c|}{$\begin{array}{c}\text { Контромьная группа } \\
\text { Control group }\end{array}$} \\
\hline & & \multicolumn{2}{|c|}{$\begin{array}{l}\text { Исходный } \\
\text { Initial }\end{array}$} & \multicolumn{2}{|c|}{$\begin{array}{c}\text { Конечный } \\
\text { Final }\end{array}$} & \multicolumn{2}{|c|}{$\begin{array}{c}\text { Исходный } \\
\text { Initial }\end{array}$} & \multicolumn{2}{|c|}{$\begin{array}{c}\text { Конечный } \\
\text { Final }\end{array}$} \\
\hline & & $\begin{array}{c}\text { KOn- } \\
\text { BO } \\
\text { Sum }\end{array}$ & $\%$ & $\begin{array}{c}\text { Kon- } \\
\text { Bo } \\
\text { Sum }\end{array}$ & $\%$ & $\begin{array}{l}\text { Кол-во } \\
\text { Sum }\end{array}$ & $\%$ & $\begin{array}{l}\text { Кол-во } \\
\text { Sum }\end{array}$ & $\%$ \\
\hline \multirow{3}{*}{$\begin{array}{l}\text { Эмоцио- } \\
\text { нальная } \\
\text { устой- } \\
\text { чивость } \\
\text { при } \\
\text { взаимо- } \\
\text { Аействии* } \\
\text { Emotional } \\
\text { stabil- } \\
\text { ity in the } \\
\text { process of } \\
\text { interaction* }\end{array}$} & $\begin{array}{l}\text { Низкий } \\
\text { Low }\end{array}$ & 9 & 30 & 0 & 0 & 13 & 43 & 0 & 0 \\
\hline & $\begin{array}{l}\text { Средний } \\
\text { Average }\end{array}$ & 21 & 70 & 11 & 37 & 17 & 57 & 17 & 57 \\
\hline & $\begin{array}{l}\text { Высокий } \\
\text { High }\end{array}$ & 0 & 0 & 19 & 63 & 0 & 0 & 13 & 43 \\
\hline
\end{tabular}




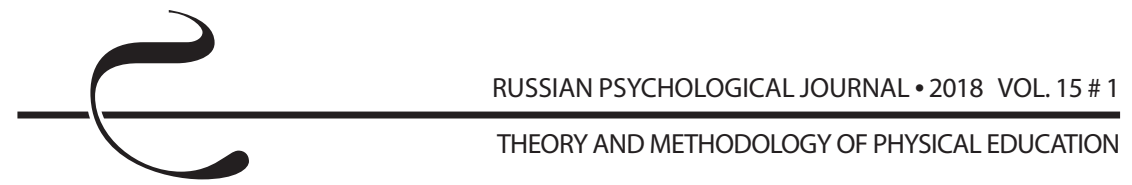

\begin{tabular}{|c|c|c|c|c|c|c|c|c|c|}
\hline \multirow{4}{*}{$\begin{array}{c}\text { Показатели } \\
\text { готовности } \\
\text { Charac- } \\
\text { teristics of } \\
\text { readiness }\end{array}$} & \multirow{4}{*}{$\begin{array}{c}\text { Уровни } \\
\text { проявле- } \\
\text { ния } \\
\text { Levels of } \\
\text { manifes- } \\
\text { tation }\end{array}$} & \multicolumn{8}{|c|}{$\begin{array}{c}\text { Этапы эксперимента } \\
\text { Experimental stages }\end{array}$} \\
\hline & & \multicolumn{4}{|c|}{$\begin{array}{c}\text { Экспериментальная } \\
\text { группа } \\
\text { Experimental group }\end{array}$} & \multicolumn{4}{|c|}{$\begin{array}{c}\text { Контрольная группа } \\
\text { Control group }\end{array}$} \\
\hline & & \multicolumn{2}{|c|}{$\begin{array}{c}\text { Исходный } \\
\text { Initial }\end{array}$} & \multicolumn{2}{|c|}{$\begin{array}{c}\text { Конечный } \\
\text { Final }\end{array}$} & \multicolumn{2}{|c|}{$\begin{array}{l}\text { Исходный } \\
\text { Initial }\end{array}$} & \multicolumn{2}{|c|}{$\begin{array}{c}\text { Конечный } \\
\text { Final }\end{array}$} \\
\hline & & $\begin{array}{l}\text { KON- } \\
\text { BO } \\
\text { Sum }\end{array}$ & $\%$ & $\begin{array}{l}\text { KOn- } \\
\text { BO } \\
\text { Sum }\end{array}$ & $\%$ & $\begin{array}{l}\text { Кол-во } \\
\text { Sum }\end{array}$ & $\%$ & $\begin{array}{l}\text { Кол-во } \\
\text { Sum }\end{array}$ & $\%$ \\
\hline \multirow{3}{*}{$\begin{array}{l}\text { Толерант- } \\
\text { ность** } \\
\text { Tolerance** }\end{array}$} & $\begin{array}{l}\text { Низкий } \\
\text { Low }\end{array}$ & 1 & 3 & 0 & 0 & 0 & 0 & 0 & 0 \\
\hline & $\begin{array}{l}\text { Средний } \\
\text { Average }\end{array}$ & 15 & 50 & 11 & 37 & 23 & 77 & 20 & 67 \\
\hline & $\begin{array}{l}\text { Высокий } \\
\text { High }\end{array}$ & 14 & 47 & 19 & 63 & 7 & 23 & 10 & 33 \\
\hline \multirow{3}{*}{$\begin{array}{l}\text { Волевые } \\
\text { качества** } \\
\text { Volitional } \\
\text { qualities** }\end{array}$} & $\begin{array}{l}\text { Низкий } \\
\text { Low }\end{array}$ & 4 & 13 & 0 & 0 & 6 & 20 & 1 & 3 \\
\hline & $\begin{array}{l}\text { Средний } \\
\text { Average }\end{array}$ & 23 & 77 & 18 & 60 & 22 & 73 & 23 & 77 \\
\hline & $\begin{array}{l}\text { Высокий } \\
\text { High }\end{array}$ & 3 & 10 & 12 & 40 & 2 & 7 & 6 & 20 \\
\hline
\end{tabular}

Примечание: * различия достоверны на уровне значимости $p=0,01$; ** различия достоверны на уровне значимости $p=0,05$.

Note: * the difference is significant at the 0.01 level; ${ }^{* *}$ the difference is significant at the 0.05 level.

В результате исследования эмоциональной устойчивости в ситуациях взаимодействия на исходном срезе было обнаружено, что $57 \%$ респондентов контрольной выборки и $70 \%$ экспериментальной отличались средним уровнем проявления данного показателя. Низкий уровень наблюдался у $43 \%$ респондентов контрольной группы и $30 \%$ экспериментальной. Высоких результатов зафиксировано не было (рисунок 1а).

Исходя из полученных результатов, можно заключить, что на исходном этапе исследования подавляющее большинство респондентов, как контрольной, так и экспериментальной групп, не владеют умениями саморегуляции, не готовы к творческому и эффективному поведению в условиях коллективного взаимодействия и ситуациях публичного оценивания. 


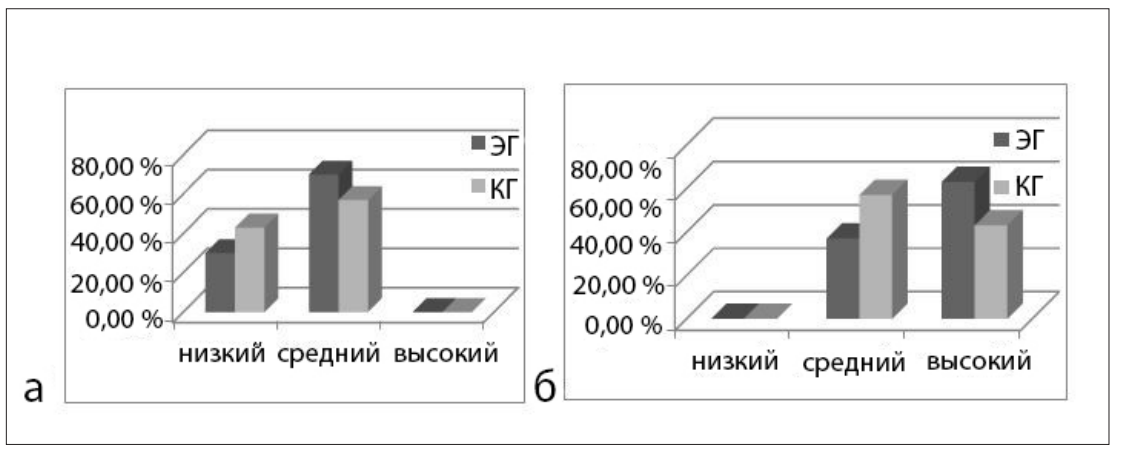

Рисунок 1. Распределение испытуемых контрольной и экспериментальной групп по уровням проявления эмоциональной устойчивости при взаимодействии: а) на исходном срезе; б) на конечном срезе

Figure 1. Distribution of the respondents from control and experimental groups by the levels of emotional stability in the process of interaction: a) initial sample; b) final sample

Однако на конечном срезе были зафиксированы противоположные результаты. Все студенты распределились на средний (57\% в контрольной и $37 \%$ в экспериментальной выборке) и высокий (43\% в контрольной и $63 \%$ в экспериментальной выборке) уровни эмоциональной устойчивости. При этом респондентов с эмоциональной неустойчивостью в ситуациях коллективного взаимодействия и оценивания зафиксировано не было (рисунок 1б).

Однако достоверно более высокие результаты (при р =0,01) были выявлены все же в экспериментальной выборке, где общий положительный прирост составил $63 \%$, что на $20 \%$ больше, чем в контрольной группе (таблица 1). Полагаем, что такой результат обусловлен снижением страха публичных выступлений, накоплением опыта профессионального взаимодействия в различных условиях и развитием умений саморегуляции (квазипрофессиональный модуль).

Анализ результатов исследования толерантности на исходном срезе свидетельствует о том, что в большинстве случаев в контрольной и экспериментальной выборках наблюдался средний уровень проявления данного показателя. Это в долевом выражении составило $67 \%$ и $50 \%$ соответственно. Высокий уровень был зафиксирован у $23 \%$ студентов контрольной группы и у $47 \%$ - экспериментальной. Низкая толерантность отмечена у $3 \%$ испытуемых экспериментальной группы, в контрольной группе таких результатов не наблюдалось (рисунок 2а). 


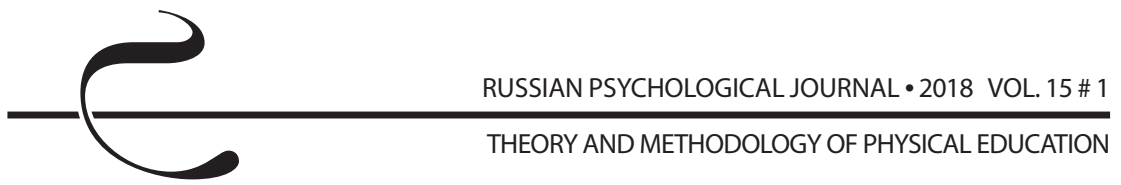

a
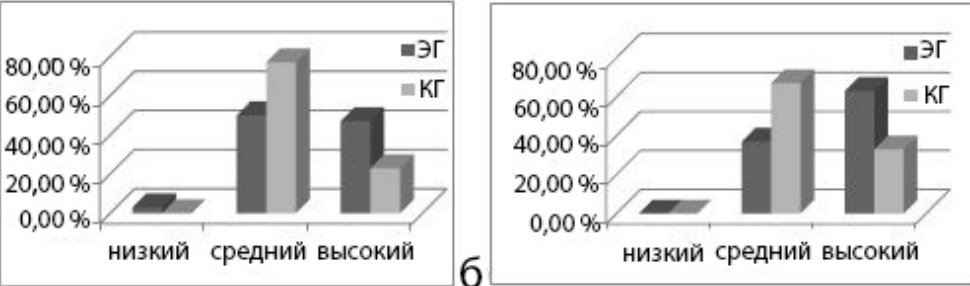

Рисунок 2. Распределение испытуемых контрольной и экспериментальной групп по уровням проявления толерантности: а) на исходном срезе; б) на конечном срезе

Figure 2. Distribution of the respondents from control and experimental groups by the levels of tolerance: a) initial sample; b) final sample

При этом у респондентов со средним уровнем характерно ситуативное проявление толерантности в чисто корпоративных рамках. Это говорит о том, что в условиях профессионального взаимодействия такие бакалавры готовы терпеть неприемлемые, по их мнению, особенности занимающихся (жизненные интересы, наличие твердого жизненного мнения, сексуальную ориентацию, привычки, внешний вид). Однако мотив долженствования приводит к значительному внутреннему напряжению. При этом, чем сильнее субъекты взаимодействия отличаются друг от друга, тем сильнее напряжение. В эмоционально-волевом контексте поведения тренера это выражается в скованности, минимализме вербального общения, осторожности, брезгливости.

Лица с высоким уровнем толерантности характеризуются безоценочным отношением к людям, которые сильно отличаются от них по поведению, образу жизни, культуре или иным признакам.

Напротив, низкий уровень проявления данного показателя характеризует интолерантного человека, который абсолютно нетерпим к недостаткам, ошибкам и другим, неприемлемым для него, особенностям партнеров по взаимодействию. При столкновении с эмоционально негативными собеседниками складывается негативная система межличностных отношений.

Таким образом, тот факт, что большинство испытуемых на исходном этапе исследования характеризовались средним с тенденцией к высокому уровнем толерантности, говорит о специфических особенностях лиц, поступающих на факультет физической культуры и спорта. Дело в том, что в среде 
спорта обязательно подразумевается конкуренция и возможно создание различных конкурентных отношений, в то время как в оздоровительной тренировке таких отношений просто не предусмотрено, и поэтому многие студенты, которые пришли на факультет из среды «физической культуры», более толерантны, общительны, доброжелательны и т. д., чем «чистые» спортсмены.

Исследование толерантности на конечном срезе из эксперимента показало достоверно более высокие результаты в экспериментальной выборке (при p = 0,05), где общий прирост составил $16 \%$, в то время как в контрольной - лишь $10 \%$. В экспериментальной группе преобладали респонденты с высокой толерантностью (63\%), в то время как в контрольной по-прежнему доминировал средний уровень проявления данного показателя (рисунок 26). Низких результатов зафиксировано не было.

Полагаем, что переход испытуемых экспериментальной группы из низкого в средний уровень (3\%) и из среднего в высокий (13\%) обусловлен применением средств и методов развивающего модуля авторской модели. Отдельные тренинги, включающие упражнения, игры, ситуационные задания, позволили повысить уровень толерантности через самопознание и взаимопознание индивидуальных различий участников занятий, осознание влияния предрассудков на восприятие людьми друг друга, понимание бессмысленной траты внутренней психической энергии на внутреннюю борьбу с вымышленным «врагом» и т. д.

Анализ результатов исследования волевых качеств на исходном срезе показал, что 73\% студентов контрольной выборки и 77\% экспериментальной характеризовались средним уровнем проявления данного показателя. Высокие результаты наблюдались у $7 \%$ респондентов в контрольной группе и $10 \%$ - в экспериментальной. Вместе с тем, низкий уровень развития волевых качеств был зафиксирован у 20\% контрольной выборки и $13 \%$ экспериментальной (рисунок За).

Для респондентов, имеющих средний уровень развития волевых качеств, характерно поверхностное проявление дисциплинированности и организованности до тех пор, пока личностные потребности или выгоды не перекроют социальные мотивы взаимодействия. Это может проявиться в будущей профессиональной деятельности в попустительском отношении к системе оздоровительных тренировок, пропуске занятий или низкой требовательности к соблюдению режима тренировки. Несмотря на то, что такие субъекты иногда нарушают временные ограничения выполнения деятельности, в целом они соблюдают установленный порядок. Настойчивость и решительность проявляются у них только в тех ситуациях, которые располагают благоприятными условиями для этого. При 


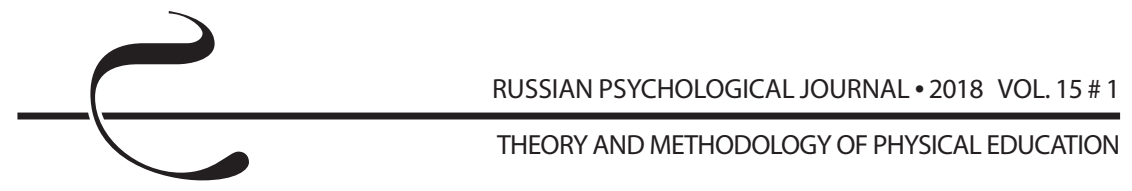

возникновении значительных препятствий в процессе взаимодействия они готовы отступить от намеченной цели и переориентировать мотивы совместной деятельности.

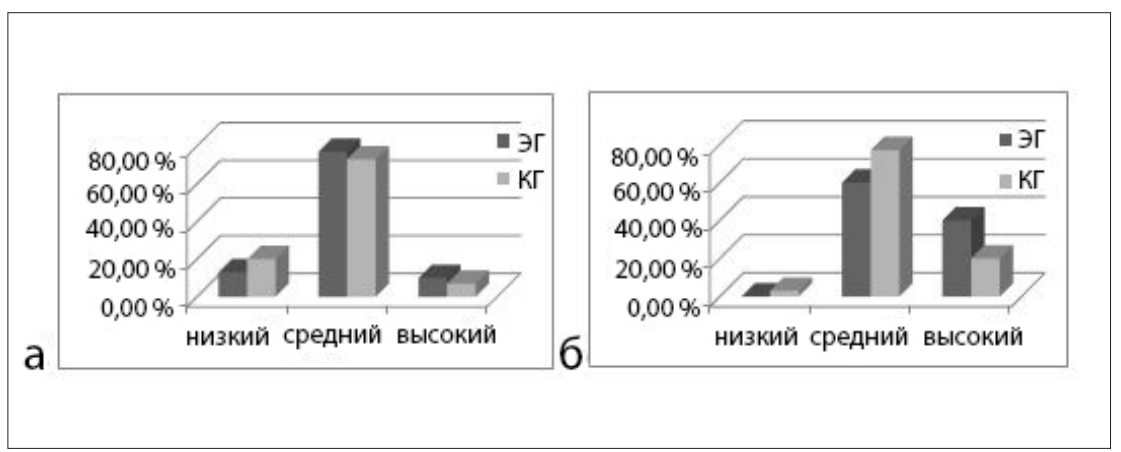

Рисунок 3. Распределение испытуемых контрольной и экспериментальной групп по уровням проявления волевых качеств: а) на исходном срезе; б) на конечном срезе

Figure 3. Distribution of the respondents from control and experimental groups by the levels of volitional qualities: a) initial sample; b) final sample

Низкие результаты по данному показателю свидетельствуют о непоследовательности и разбросанности поведения. Слаборазвитая самодисциплина, стихийное управление своей деятельностью, неспособность к борьбе с трудностями говорят о незрелости личности и неспособности к автономной жизнедеятельности. Такой уровень развития волевых качеств является недопустимым для полисубъектного взаимодействия тренера и занимающихся в системе оздоровительных тренировок.

Напротив, высокий уровень проявления волевых качеств означает зрелость, активность, независимость, самостоятельность личности респондентов. Они всегда строго соблюдают дисциплину и требуют того же от партнеров по взаимодействию, стремятся к выполнению намеченного независимо от сложности процесса. В большинстве ситуаций решительны и непоколебимы. Такие субъекты умело управляют не только своими состояниями, но и способны побуждать к активности партнеров по взаимодействию, поддерживая необходимый режим совместной деятельности.

На конечном срезе достоверно более высокие результаты были зафиксированы в экспериментальной выборке (при р =0,05), где общий прирост составил $30 \%$, в то время как в контрольной - только $17 \%$ (рисунок 36). 


\section{Обсуждение результатов}

В силу специфики полученных эмпирических данных, следует отдельно проанализировать причины, вызвавшие такие большие изменения в двух выборках одновременно.

На наш взгляд, уровень проявления эмоциональной устойчивости в условиях публичных выступлений тесно связан с возрастными особенностями формирования Я-концепции в совокупности с профессиональной неготовностью студентов. Так, на исходном срезе возрастной диапазон испытуемых составил 17-19 лет. В это время значительную роль в формировании самооценки личности играет социальный фактор «Что обо мне скажут окружающие?». В юношеском возрасте характерны завышенные притязания в сфере социального взаимодействия и образования, обостренные ощущения уникальности, амбициозность, самолюбие (в противоположном случае - замкнутость и самобичевание) [27]. Студенты озабочены тем, какое место им отводится в учебно-профессиональной иерархии, как их оценивают сокурсники и как это согласуется с собственной самооценкой. В условиях коллективного взаимодействия и ситуациях оценивания группой при отсутствии знаний, умений и опыта профессионального взаимодействия появляется боязнь опозориться, выглядеть глупо и, как следствие, потерять свой статус, что в свою очередь делает личность студента уязвимой в таких условиях, разрушает его психоэмоциональное состояние и способствует психической напряженности. Поэтому большинство респондентов экспериментальной и контрольной групп показали низкие результаты на исходном этапе эксперимента.

К концу обучения фактор мнения окружающих теряет свою актуальность, на первый план выходит самооценка первых жизненных достижений (результаты учебы, создание семьи, спортивные успехи), важными становятся проблемы вступления в трудовую деятельность [27]. Студент уже чувствует себя уверенно в ситуациях коллективного взаимодействия, т. к. в процессе профессиональной подготовки произошло повышение компетентности, накопился опыт профессионального взаимодействия с субъектами тренировки. Таким образом, можно сделать вывод, что вышеизложенные особенности профессионально-личностного развития бакалавров физической культуры отразились в значительной динамике развития эмоциональной устойчивости у респондентов обеих групп.

В первую очередь следует отметить особую роль последовательной реализации индивидуальной и коллективной форм микропреподавания. Первым этапом в преодолении студентами стеснения и страха публичных выступлений было индивидуальное проведение маленьких фрагментов оздоровительной тренировки внутри своей группы. Так как основной 
причиной такого рода боязни является неуверенность в своем мастерстве, страх допустить ошибку или выглядеть глупо, то, чтобы избежать этого, студенты были вынуждены тщательно готовиться к микропреподаванию: готовить конспекты, продумывать и тренироваться для проведения части групповых или индивидуальных тренировок. Это, с одной стороны, развивало у них конструктивные навыки, а с другой - уверенность в себе. Вторым этапом в решении проблемы эмоциональной устойчивости в условиях группового взаимодействия стало коллективное проведение физкультурнооздоровительных занятий в группах обучающихся по другим направлениям подготовки. Такая форма микропреподавания способствовала, на наш взгляд, постепенному снятию комплексов выступлений перед незнакомой аудиторией, предполагала взаимопомощь и поддержку соучастников группы, свободный выбор индивидуальной задачи, в зависимости от интересов, желаний и своих возможностей. Кроме того, коллективная форма работы учила стратегиям сотрудничества и взаимопомощи, при которых обычно происходит взаимное обучение и воспитание своих товарищей по совместной работе [28].

Вместе с тем, большое значение в повышении эмоциональной устойчивости будущих бакалавров имело внедрение в процесс физического воспитания средств йоги, калланетики, пилатеса. Арсенал данных низкоинтенсивных фитнес-программ богат широким спектром упражнений, направленных на одновременное развитие всех групп мышц, укрепление суставно-связочного аппарата и оптимизацию работы сердечно-сосудистой системы человека и в их специфическом влиянии на эмоционально-волевую сферу занимающихся [29, 30]. Выполнение многофункциональных упражнений в статическом режиме или удержание определенных, часто неудобных, поз (в йоге - асан) сопровождается нервно-психическим напряжением, которое по силе воздействия на нервную систему может совпадать с эмоциональным состоянием в трудных профессиональных ситуациях полисубъектного взаимодействия. Занятия такими упражнениями требуют активизации эмоционально-волевых усилий, чтобы абстрагироваться от неприятных ощущений или эмоциональных переживаний. Сознательный контроль мышечного тонуса посредством рационального распределения нервно-психического напряжения значительно снижает нагрузку на нервную систему за счет использования приемов саморегуляции (самоприказов, дыхательных упражнений, воспроизведения в воображении ситуаций прошлого положительного эмоционального переживания, переключения с неприятных мышечных ощущений на активное слушание фоновой медленной музыки и т. д.). Таким образом, систематические занятия такими упражнениями способствовали развитию волевых качеств 
бакалавра - терпеливости, спокойствия и выдержки, что особенно важно при взаимодействии с незнакомой аудиторией или большим количеством занимающихся.

Следует добавить, что формирование эмоциональной устойчивости в условиях взаимодействия с незнакомой аудиторией, в ситуациях публичного выступления или оценивания окружающими также возможно вследствие накопления опыта участия в физкультурно-оздоровительных и рекреационных мероприятиях в качестве ведущих. Как отмечал К.С. Станиславский, «публичные выступления обладают свойством закреплять, фиксировать то, что происходит на сцене и внутри самого артиста. Всякое действие или переживание, проделанное с творческим или иным волнением, вызываемым присутствием толпы, запечатлевается в эмоциональной памяти сильнее, чем в обычной, репетиционной, или в домашней обстановке. Поэтому как ошибки, так и удачи, совершенные на сцене $<\ldots$. , закрепляются прочнее на публике» [26, с. 170].

Таким образом, можно сделать вывод об эффективности вышеперечисленных средств и методов квазипрофессионального модуля авторской модели в формировании эмоциональной устойчивости у будущих бакалавров физической культуры.

Полагаем, что повышение уровня развития волевых качеств у будущих бакалавров физической культуры в процессе реализации экспериментальной авторской модели произошло в силу следующих причин:

- приобретены знания в области психологических трудностей тренера, эмоционально-волевой регуляции, управления негативными психофизиологическими состояниями в условиях полисубъектного взаимодействия с субъектами оздоровительной тренировки (информационный модуль);

- внедрены упражнения, направленные на развитие целеполагания и самомотивации в процесс практических занятий (развивающий модуль), что, на наш взгляд, способствовало развитию целеустремленности студентов;

- реализованы тренинги и психотехнические игры, способствующие развитию веры в свои силы, чувству успеха, позитивному мышлению, что отразилось на формировании решительного и настойчивого поведения (развивающий модуль);

- студенты вовлечены в творческую деятельность, стимулирующую развитие организованности и дисциплинированности (квазипрофессиональный модуль). Условия, где свобода самовыражения и реализации замыслов, поиск идей и возможностей для выполнения задания ограничены только временем предъявления работ, стимулировали проявление самоорганизации и самоконтроля собственной деятельности. 


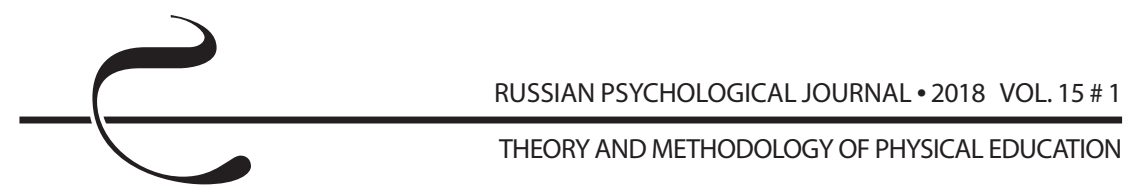

Достоверно более высокие результаты у респондентов экспериментальной выборки доказывают эффективность методов и средств формирования эмоционально-волевой готовности бакалавров физической культуры к полисубъектному взаимодействию.

Таким образом, необходимость развития эмоционально-волевой готовности будущих бакалавров физической культуры к полисубъектному взаимодействию определяется спецификой их профессиональной деятельности: высокой вероятностью возникновения стресс-факторов, стихийностью процесса взаимодействия, непредсказуемостью профессиональных ситуаций, эмоциональной насыщенностью, высоким уровнем ответственности в совокупности со значительными физическими нагрузками. Авторами была разработана специфическая технология формирования эмоционально-волевой готовности к полисубъектному взаимодействию, которая способствовала развитию у студентов факультета физической культуры эмоциональной устойчивости при взаимодействии с незнакомой аудиторией субъектов оздоровительной тренировки, толерантности и волевых качеств. Апробация разработанной технологии позволила подтвердить эффективность в процессе формирования уровней эмоционально-волевой готовности: низкого, среднего и высокого на уровне статистической значимости при $p \geq 0,05$.

\section{Литература}

1. Валеева Г. В., Тюмасева 3. И., Орехова И. Л. Развитие психологической готовности студентов педагогического вуза к оздоровительной работе в образовательных организациях // Здоровьесберегающее образование: научно-практический журнал. - 2011. - № 4. - С. 53-59.

2. Валеева Г. В. Система развития психологической готовности к оздоровительной деятельности в аспекте высшего педагогического образования // Педагогическое образование в России. - 2014. - № 2. C. 11-17.

3. Макеева В. С., Токарева К. Е., Поляков Д. О. Формирование готовности к полисубъектному взаимодействию бакалавра физической культуры // Современные проблемы науки и образования. - 2015. - № 4. - URL: https:// science-education.ru/ru/article/view?id=20869 (дата обращения: 09.02.2018).

4. Макеева В. С., Токарева К. Е., Пушкина В. Н. Развитие организации полилога субъектов оздоровительной тренировки // Известия Российского государственного педагогического университета им. А. И. Герцена. 2016. - № 179. - C. 151-158.

5. Макеева В. С., Токарева К. Е., Пушкина В. Н., Корнев А. В. Особенности формирования готовности кполисубъектной организации оздоровительной 
тренировки будущего бакалавра физической культуры //Ученые записки университета имени П. Ф. Лесгафта. - 2015. - № 12 (130). - С. 131-138.

6. Усцелемова Н. А., Иванова Е. А. Физкультурно-спортивная деятельность как средство формирования у будущих бакалавров физической культуры профессиональной устойчивости // Вестник Оренбургского государственного университета. - 2017. - № 3 (203). - С. 20-24.

7. Чекмарева T. Н., Фалунина Е. В. Актуализация проблемы развития толерантности личности у будущих педагогов в условиях высшего профессионального образования // Вектор науки Тольяттинского гос. ун-та. Сер. Педагогика и психология. - 2013. - № 4 (26). - С. 295-299.

8. Карпюк $R$. Теоретичні засади професійної готовності до педагогічної діяльності майбутніх фахівців з адаптивного фізичного виховання // Фізичне виховання, спорт і культура здоров'я у сучасному суспільстві. 2008. - T. 1. - C. 178-180.

9. Richmond V. P., McCroskey J. C. Nonverbal Behavior in Interpersonal Relations. - MA : Allyn and Bacon, 2000. - 4th ed. - 356 p.

10. Вахитова Г. Х. Полисубъектное взаимодействие в контексте предшкольного образования // Вестник ТГПУ. - 2013. - № 13 (141). - С. 71-75.

11. Вачков И. В. Полисубъектный подход к педагогическому взаимодействию // Вопросы психологии. - 2007. - № 3. - С. 16-29.

12. Иванова С. П. Полисубъектное взаимодействие в социально-педагогической среде как фактор развития профессионально-личностной компетентности учителя // Вестник Псковского государственного университета. - 2013. - № 3. - С. 161-170.

13. Мухаметзянова Ф. Г., Мифтахов И.И. Феномен субъектности студента в психологии // Казанский педагогический журнал. - 2013. - № 4. - С. 126-130.

14. Невдах С. И. Полисубъектное взаимодействие в образовательной среде учреждения дополнительного образования взрослых // Вестник МГПУ. Серия «Педагогика и психология». - 2011. - № 4 (18). - С. 56-62.

15. Харланова Е. М. Полисубъектное управление педагогическим обеспечением развития социальной активности студентов // Педагогическое образование в России. - 2011. - № 5. - С. 212-217.

16. Хохлова М. В. Субъектный опыт сотрудничества в структуре готовности к профессиональной деятельности бакалавра // Вестник Брянского государственного университета. - 2014. - № 1. - С. 268-272.

17. Шаруева Е. В. Организационно-педагогические условия готовности педагогов к полисубъектному взаимодействию // Современное образование: актуальные вопросы, достижения и инновации : сборник статей победителей VIII международной научно-практической конференции. - Пенза : Наука и Просвещение, 2017. - С. 26-29. 
18. ШелеховаЛ. В. Полисубъектное взаимодействие какмеханизм эффективности учебно-познавательной деятельности студентов // Известия Южного федерального университета. Педагогические науки. - 2009. - № 9. - С. 213-219.

19. Аксенова Г. И. Субъектно-деятельностный подход к профессиональному образованию курсантов // Прикладная юридическая психология. 2008. - № 1. - С. 26-33.

20. Давыдова С. А. Готовность педагога по физической культуре к здоровьесберегающей деятельности // Теория и практика общественного развития. - 2014. - № 20. - С. 185-188.

21. Gabana N. A Strengths-Based Cognitive Behavioral Approach to Treating Depression and Building Resilience in Collegiate Athletics: The Individuation of an Identical Twin // Case Studies in Sport and Exercise Psychology. 2017. - Vol. 1, Issue 1. - P. 4-15. DOI: 10.1123/cssep.2016-0005

22. Toxirov A., Durmanov A. The development of the education and training system, innovative management and organizational factors // Наука и современное общество: взаимодействие и развитие. - Уфа: Ника, 2015. - № 1 (2). - C. 87-89.

23. Valiev R. A., Valieva T. V., Maksimova L. A., Karimova V. G. Readiness for interaction with inoethnic subjects of education and ethnic worldview // Psychology in Russia: State of the Art. - 2016. - Vol. 9 (1). - P. 138-154. DOI: 10.11621/pir.2016.0110

24. Оплетин А. А. Формирование механизма предметных физкультурно спортивной компетенции и компетенции саморазвития средствами физической культуры // Педагогико-психологические и медико-биологические проблемы физической культуры и спорта. - 2017. - Т. 12, № 1. - С. 68-73.

25. Атамась О. Структурні компоненти готовності майбутніх учителів фізичної культури до впровадження технологій оздоровчого фітнесу // Фізичне виховання, спорт і культура здоров'я у сучасному суспільстві. 2012. - № 2 (18). - С. 38-42.

26. Станиславский К. С. Работа актера над собой в творческом процессе переживания. Дневник ученика. - М. : Прайм-Еврознак, 2010. - 179 с.

27. Палачева Т. И., Жиляев А. Г. Формирование «Я - концепции» в детском, подростковом и юношеском возрастах // Молодой ученый. - 2010. - Т. 2, № 1-2 (13). - С. 208-214.

28. Аббасова А. А. Дискуссионная методика в русле инновационных лингводидактических тенденций, систем, моделей гуманистического полисубъектного взаимодействия : дисс. ... канд. пед. наук. - М., 2016. - 225 с.

29. Gulhane T. F. Yoga and Physical Fitness // International Journal of Applied Research. - 2015. - Vol. 1, Issue 5. - P. 129-130. 
30. Richardson C. R., Faulkner G., McDevitt J., Skrinar G. S., Hutchinson D. S., Piette J. D. Integrating Physical Activity Into Mental Health Services for Persons With Serious Mental Illness // Psychiatric Services. - 2005. - Vol. 56, Issue 3. - P. 324-331. DOI: 10.1176/appi.ps.56.3.324

\section{References}

1. Valeeva G. V., Tyumaseva Z. I., Orekhova I. L. Psychological readiness for health-improving work in educational institutions among pedagogical high school students. Zdorov'esberegayushchee obrazovanie: nauchno-prakticheskii zhurnal - Health Saving Education: Theoretical and Practical Journal, 2011, no. 4, pp. 53-59 (in Russian).

2. Valeeva G. V. System of the development of psychological readiness for health-improving activities in higher pedagogical education. Pedagogicheskoe obrazovanie v Rossii - Pedagogical Education in Russia, 2014, no. 2, pp. 11-17 (in Russian).

3. Makeeva V. S., Tokareva K. E., Polyakov D. O. Formation of readiness for polysubject interaction among bachelors in physical education. Modern Problems of Science and Education, 2015, no. 4. Available at: https://scienceeducation.ru/ru/article/view?id=20869 (Accessed 09 February 2018).

4. Makeeva V. S., Tokareva K. E., Pushkina V. N. Organizing the polylogue for the subjects of health-improving workouts. Izvestiya Rossiiskogo gosudarstvennogo pedagogicheskogo universiteta im. A. I. Gertsena - Izvestia: Herzen University Journal of Humanities \& Science, 2016, no. 179, pp. 151-158 (in Russian).

5. Makeeva V. S., Tokareva K. E., Pushkina V. N., Kornev A. V. Readiness for the organization of a polysubject health-improving workout among future bachelors in physical education. Uchenye zapiski universiteta imeni P. F. Lesgafta, 2015, no. 12 (130), pp. 131-138 (in Russian).

6. Ustselemova N. A., Ivanova E. A. Sports activities as a means of formation of professional stability among future bachelors in physical education. Vestnik Orenburgskogo gosudarstvennogo universiteta - Vestnik of the Orenburg State University, 2017, no. 3 (203), pp. 20-24 (in Russian).

7. Chekmareva T. N., Falunina E. V. Actualization of the problem of the development of tolerance among future teachers in higher professional education. Vektor nauki Tol'yattinskogo gos. un-ta. Ser. Pedagogika ipsikhologiya-Science Vector of Togliatti State University. Series: Pedagogy, Psychology, 2013, no. 4 (26), pp. 295-299 (in Russian).

8. Karpjuk R. Theoretical bases of professional readiness for pedagogical activity among future specialists in adaptive physical education. Fizichne vikhovannia, sport i kul'tura zdorov'ia u suchasnomu suspil'stvi - Physical Education, Sport and Health Culture in Modern Society, 2008, V. 1, pp. 178-180 (in Ukrainian). 
9. Richmond V. P., McCroskey J. C. Nonverbal behavior in interpersonal relations. MA, Allyn and Bacon, 2000. 356 p.

10. Vakhitova G. Kh. Polysubject interaction in the context of pre-school education. Vestnik TGPU - Tomsk State Pedagogical University Bulletin, 2013, no. 13 (141), pp. 71-75 (in Russian).

11. Vachkov I. V. Polysubject approach to pedagogical interaction. Voprosy Psychologii, 2007, no. 3, pp. 16-29 (in Russian).

12. Ivanova S. P. Polysubject interaction in the socio-pedagogical environment as a factor for the development of professional and personal competence of teachers. Vestnik Pskovskogo gosudarstvennogo universiteta - Bulletin of the Pskov State University, 2013, no. 3, pp. 161-170 (in Russian).

13. Mukhametzyanova F. G., Miftakhov I. I. The phenomenon of a student's subjectivity in psychology. Kazanskii pedagogicheskii zhurnal - Kazan Pedagogical Journal, 2013, no. 4, pp. 126-130 (in Russian).

14. Nevdakh S. I. Polysubject interaction in the educational environment of the additional education for adults. Vestnik MGPU. Seriya "Pedagogika i psikhologiya" - Vestnik of Moscow City University. Series: Pedagogy and Psychology, 2011, no. 4 (18), pp. 56-62 (in Russian).

15. Kharlanova E. M. Polysubject pedagogical management of the development of students' social activity. Pedagogicheskoe obrazovanie v Rossii - Pedagogical Education in Russia, 2011, no. 5, pp. 212-217 (in Russian).

16. Khokhlova M. V. A bachelor's subjective experience of cooperation in the structure of readiness for professional activity. Vestnik Bryanskogo gosudarstvennogo universiteta - The Bryansk State University Herald, 2014, no. 1, pp. 268-272 (in Russian).

17. Sharueva E. V. Organizatsionno-pedagogicheskie usloviya gotovnosti pedagogov k polisub"ektnomu vzaimodeistviyu [Organizational and pedagogical conditions of teachers' readiness for polysubject interaction]. Sbornik statei pobeditelei VIII mezhdunarodnoi nauchno-prakticheskoi konferentsii "Sovremennoe obrazovanie: aktual'nye voprosy, dostizheniya i innovatsii" [Proc. the 8th International Theoretical and Practical Conference "Modern education: Current issues, achievements, and innovations"]. Penza, Nauka i Prosveshchenie Publ., 2017, pp. 26-29.

18. Shelekhova L. V. Polysubject interaction as the mechanism of the effectiveness of students' educational and cognitive activity. Izvestiya Yuzhnogo federal'nogo universiteta. Pedagogicheskie nauki - Proceedings of South Federal University: Pedagogical sciences, 2009, no. 9, pp. 213-219 (in Russian).

19. Aksenova G. I. The subject activity approach to cadets' professional education. Prikladnaya yuridicheskaya psikhologiya - Applied Legal Psychology, 2008, no. 1, pp. 26-33 (in Russian). 
20. Davydova S. A. A teacher's in physical education readiness for healthimproving activity. Teoriya i praktika obshchestvennogo razvitiya - Theory and Practice of Social Development, 2014, no. 20, pp. 185-188 (in Russian).

21. Gabana N. A Strengths-based cognitive behavioral approach to treating depression and building resilience in collegiate athletics: The individuation of an identical twin. Case Studies in Sport and Exercise Psychology, 2017, V. 1, Issue 1, pp. 4-15. DOI: 10.1123/cssep.2016-0005

22. Toxirov A., Durmanov A. The development of the education and training system, innovative management and organizational factors. Nauka i sovremennoe obshchestvo: vzaimodeistvie i razvitie - Science and Modern Society: Interaction and Development, 2015, no. 1 (2), pp. 87-89.

23. Valiev R. A., Valieva T. V., Maksimova L. A., Karimova V. G. Readiness for interaction with inoethnic subjects of education and ethnic worldview. Psychology in Russia: State of the Art, 2016, V. 9 (1), pp. 138-154. DOI: 10.11621/ pir.2016.0110

24. Opletin A. A. The formation of the mechanism of the subject sports competence and the self-development competence by means of physical education. Pedagogiko-psikhologicheskie i mediko-biologicheskie problemy fizicheskoi kul'tury i sporta - The Russian Journal of Physical Education and Sport (Pedagogical-Psychological and Medico-Biological Problems of Physical Culture and Sports), 2017, V. 12, no. 1, pp. 68-73 (in Russian).

25. Atamas' O. Structural components of readiness for the implementation of health-improving fitness technologies among future teachers in physical education. Fizichne vikhovannia, sport i kul'tura zdorov'ia u suchasnomu suspil'stvi - Physical Education, Sport and Health Culture in Modern Society, 2012, no. 2 (18), pp. 38-42 (in Ukrainian).

26. Stanislavskii K. S. Rabota aktera nad soboi v tvorcheskom protsesse perezhivaniya. Dnevnik uchenika [The actor's work on himself/herself in the creative process of experience: a student's diary]. Moscow, Praim-Evroznak Publ., 2010. 179 p.

27. Palacheva T. I., Zhilyaev A. G. Self-concept in childhood, adolescence, and youth. Molodoi uchenyi - Young Scientist, 2010, V. 2, no. 1-2 (13), pp. 208-214 (in Russian).

28. Abbasova A. A. Diskussionnaya metodika v rusle innovatsionnykh lingvodidakticheskikh tendentsii, sistem, modelei gumanisticheskogo polisub"ektnogo vzaimodeistviya [Discussion methods in innovative didactic tendencies, systems, and models of humanistic polysubject interaction]. Diss. Cand. Sci. (Pedag.). Moscow, 2016. 225 p.

29. Gulhane T. F. Yoga and physical fitness. International Journal of Applied Research, 2015, V. 1, Issue 5, pp. 129-130. 
30. Richardson C. R., Faulkner G., McDevitt J., Skrinar G. S., Hutchinson D. S., Piette J. D. Integrating physical activity into mental health services for persons with serious mental illness. Psychiatric Services, 2005, V. 56, Issue 3, pp. 324-331. DOI: 10.1176/appi.ps.56.3.324 